\title{
Methanolic Extract of Leathery Murdah, Terminalia coriacea (Roxb.) Wight and Arn. Leaves Exhibits Anti-Inflammatory Activity in Acute and Chronic Models
}

\author{
Mohammed Safwan Ali Khan ${ }^{\mathrm{a}-\mathrm{c}}$ Nishath Khatoon ${ }^{\mathrm{c}}$ Mohammad M. Al-Sanea $^{\mathrm{d}}$ \\ Mohamed Gamal Mahmoud ${ }^{d}$ Hidayat Ur Rahman ${ }^{\text {a }}$

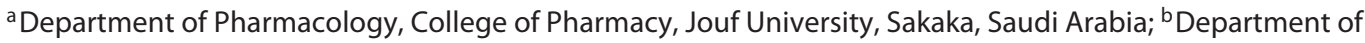 \\ Biomedical Sciences, Faculty of Medicine and Health Sciences, Universiti Putra Malaysia, Serdang, Malaysia; \\ 'Department of Pharmacology, Anwarul Uloom College of Pharmacy affiliated to Jawaharlal Nehru Technological

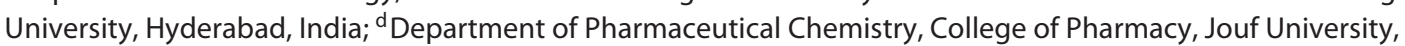 \\ Sakaka, Saudi Arabia
}

\section{Significance of the Study}

- Anti-inflammatory activity of methanolic extract of Terminalia coriacea was evaluated in acute and chronic inflammation models. The methanolic extract of $T$. coriacea leaves exhibited antitransudative and antiproliferative effects and also reduced edema induced by carrageenan. Thus, T. coriacea and its components could be potential agents for the treatment of inflammation.

\section{Keywords}

Anti-inflammatory activity · Terminalia coriacea .

Carrageenan · Granuloma

\begin{abstract}
Objective: The aim of the present study was to evaluate anti-inflammatory activity of methanolic extract of Terminalia coriacea. Materials and Methods: A methanolic extract of $T$. coriacea leaves was studied in albino Wistar rats with carrageenan-induced paw edema, an acute model, and cotton pellet-induced granuloma, a chronic model, at 3 oral test doses $(125,250$, and $500 \mathrm{mg} / \mathrm{kg})$. Aspirin $100 \mathrm{mg} / \mathrm{kg}$ was used as a positive control. Paw volume and wet and dry weights of cotton pellets were determined. The data were analyzed by one-way ANOVA followed by Dunnett's multi-
\end{abstract}

\begin{tabular}{ll}
\hline KARGER & (c) 2018 The Author(s) \\
Published by S. Karger AG, Basel & Karger \\
E-Mail karger@karger.com & $\begin{array}{l}\text { This is an Open Access article licensed under the Creative Commons } \\
\text { Attribution-NonCommercial-4.0 International License (CC BY-NC) } \\
\text { (http://www.karger.com/Services/OpenAccessLicense), applicable to } \\
\text { the online version of the article only. Usage and distribution for } \\
\text { commercial purposes requires written permission. }\end{array}$
\end{tabular}

ple comparison test. Results: The test extract at doses of 125 and $250 \mathrm{mg} / \mathrm{kg}$ decreased paw volume and wet and dry weights of cotton pellets. The highest test dose $(500 \mathrm{mg} / \mathrm{kg}$ ) displayed a response comparable to that of the standard drug $(p<0.01)$ on paw volume. The extract produced similar $(p<0.05)$ decrease in wet weight of the cotton pellet at 125 and $250 \mathrm{mg} / \mathrm{kg}$, whereas the effect of $500 \mathrm{mg} / \mathrm{kg}$ of the extract was comparable to that of aspirin $100 \mathrm{mg} / \mathrm{kg}(p<0.01)$. The extract of $T$. coriacea at $500 \mathrm{mg} / \mathrm{kg}$ induced the most significant $(p<0.01)$ effect on wet weight of granulomatous tissue. Conclusion: The methanolic extract of $T$. coriacea leaves successfully decreased paw edema as well as dry and wet weights of granulomatous tissue in both acute and chronic inflammatory models thus confirming the antiedematogenic, antitransudative, and antiproliferative properties of $T$. coriacea.

(c) 2018 The Author(s)

Published by S. Karger AG, Basel
Mohammed Safwan Ali Khan

Department of Pharmacology

College of Pharmacy, Jouf University

Sakaka 2014, Al Jouf Province (Saudi Arabia)

E-Mail mskhan@ju.edu.sa or safwan.aucp@gmail.com 


\section{Introduction}

Leathery Murdah, Terminalia coriacea (Roxb.) Wight and Arn. belonging to the Combretaceae family is found in dry and warm parts of Andhra Pradesh and Tamil Nadu in India. In traditional medicine, the plant is used as cardiac stimulant and to treat atonic diarrhea, callous ulcers, and inflammatory conditions [1,2]. Recent pharmacological investigations on the methanolic extract of $T$. coriacea leaves revealed antinociceptive [3], wound healing [4], anticonvulsant [5], anti-ulcer [6], and hepatoprotective potentials [7]. Phytochemical studies had revealed the presence of bioactive compounds such as flavonoids like apigenin, kaempferol, luteolin, myricetin, quercetin, rutin [6], 1H-inden-1-one,2,3-dihydro-3,3,5,6,-tetramethyl; levoglucosan; neophytadiene; phytol; hexadecanoic acid; n-hexadecanoic acid; stigmasterol; $ß$-sitosterol [8]; betulic acid, arjunic acid, arjunolic acid, arjunetin, ellagic acid [9], gallic acid, procyanidin $\mathrm{B}_{1}, \mathrm{~B}_{2}$, and $\mathrm{B}_{3}$, resveratrol, tyrosine [10]; raffinose; 1,2-benzene dicarboxylic acid; undecanoic acid; (2-propyl-1,3-dioxolan-2-yl)acetic acid; 2,2-dimethyl propane, and octadecatrienoic acid [11]. Based on the rich phytochemical nature and traditional use in inflammation, the present study was conducted to evaluate antiinflammatory activity of methanolic extract of $T$. coriacea in acute and chronic inflammatory models.

\section{Material and Methods}

\section{Plant Material and Extraction}

Fresh leaves of Leathery Murdah, T. coriacea (Roxb.) Wight and Arn. (synonyms - T. alata, T. crenulata, T. elliptica, and T. tomentosa) belonging to the Combretaceae family were collected from Talakonda forest, Tirumala Hills, Tirupati, Andhra Pradesh, India. The plant material was authenticated by a plant taxonomist, Dr. P. V. Prasanna of the Botanical Survey of India, Deccan Regional Centre, Hyderabad (Ministry of Environment and Forests, Government of India). The specimen deposited in the herbarium was assigned voucher No. BSID 882. Leaves of T. coriacea were washed, dried in the shade for 7 days, and then weighed. Approximately $1 \mathrm{~kg}$ of dried leaves were ground into a coarse powder using a mechanical grinder and passed through a No. 40 sieve to get the powder of desired coarseness, and then preserved in an airtight container. Approximately, $120 \mathrm{~g}$ of the powder was macerated in $600 \mathrm{~mL}$ of methanol (solvent) at a ratio of 1:5 and allowed to stand for $72 \mathrm{~h}$ and later boiled for $5 \mathrm{~h}$ [3]. The solution was filtered to obtain a decoction which was concentrated to a syrupy liquid in a water bath. The concentrated methanolic extract was then weighed. Distilled water was used to prepare a solution for the screening of anti-inflammatory activity.

\section{Animals}

A total of 60 adult male albino Wistar rats weighing 150-200 g were used for the assessment of anti-inflammatory activity. The rats were fed standard pellet diet with free access to drinking water.
Five groups of 6 rats were used in both experiments. The Institutional Animal Ethics Committee, Anwarul Uloom College of Pharmacy, Hyderabad, India, approved the study.

\section{Acute Oral Toxicity and Selection of Test Doses}

The reported maximum oral safe dose is $20,000 \mathrm{mg} / \mathrm{kg}$ [6]. Three test doses 125, 250, and $500 \mathrm{mg} / \mathrm{kg}$ were selected for the assessment of anti-inflammatory activity, with the highest test dose being 1/40th of the maximum oral safe dose. These 3 doses were used previously for the evaluation of antinociceptive [3], anti-epileptic [5] and gastroprotective activities [6].

\section{Carrageenan-Induced Paw Edema Model}

Acute inflammation in experimental animals was induced by the carrageenan-induced edema model $[12,13]$. Five groups, each containing 6 animals, were used in this experiment. The rats in the negative control group were injected normal saline $(0.9 \% \mathrm{w} / \mathrm{v}$ $\mathrm{NaCl}_{2} \mathrm{~mL} / \mathrm{kg}$ ), and aspirin at a dose of $100 \mathrm{mg} / \mathrm{kg}$ was administered to the positive control group. Three test groups received the extract at doses of 125,250 , and $500 \mathrm{mg} / \mathrm{kg}$. Subplantar injection of $0.1 \mathrm{~mL}$ of $1 \%$ suspension of carrageenan in normal saline was used to produce acute inflammation in the left hind paw of the rats $1 \mathrm{~h}$ after oral administration of the respective treatments. Paw volume was measured using a plethysmometer (UGO Basile S.R.L. Samitek Instrument, Italy) before (baseline) and after treatment

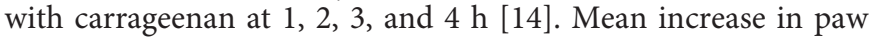
volume was calculated, and percentage inhibition was determined using the formula of Olajide et al. [15].

$$
\text { Percentage inhibition }=\frac{\left[\left(\mathrm{C}_{\mathrm{t}}-\mathrm{C}_{0}\right)_{\text {control }}-\left(\mathrm{C}_{\mathrm{t}}-\mathrm{C}_{0}\right)_{\text {treated }}\right]}{\left[\left(\mathrm{C}_{\mathrm{t}}-\mathrm{C}_{0}\right)_{\text {control }}\right]} \times 100 \text {, }
$$

where $C_{t}=$ mean paw volume for each group at time $\mathrm{t}$ and $\mathrm{C}_{0}=$ mean paw volume for each group before carrageenan injection.

\section{Cotton Pellet-Induced Granuloma Model}

The cotton pellet-induced granuloma model was adopted to induce chronic inflammation in experimental animals. The methods described by Meier et al. [16] and Niemegeers et al. [17] were used with slight modifications. Thirty rats were divided into 5 groups, each containing 6 animals. Rats in the negative control group received normal saline orally $(0.9 \% \mathrm{w} / \mathrm{v} \mathrm{NaCl} 2 \mathrm{~mL} / \mathrm{kg})$, the positive group received aspirin orally $(100 \mathrm{mg} / \mathrm{kg}$, p.o.), while the 3 test groups were treated with the extract at doses of 125, 250, and $500 \mathrm{mg} / \mathrm{kg}$ orally for 5 consecutive days. On day 1 , a sterilized cotton pellet weighing $30 \mathrm{mg}$ was introduced subcutaneously into the dorsal part of rats under ether anesthesia by the procedure described by Shaik Mossadeq et al. [18]. On the 6th day, the animals were subjected to light ether anesthesia, and the wet cotton pellets were removed and weighed to measure the antitransudative effect. These pellets were later dried for $2 \mathrm{~h}$ at $60^{\circ} \mathrm{C}$ in a hot air oven and weighed again to determine the dry weights of the cotton pellets, which correspond to the antiproliferative effect. Percentage inhibition was calculated using the formula of Okoli et al. [19].

$$
\text { Percentage inhibition }=\frac{\mathrm{Tc}-\mathrm{Tt}}{\mathrm{Tc}} \times 100 \text {, }
$$

where $\mathrm{Tc}=$ weight of granuloma tissue of the control group and $\mathrm{Tt}=$ weight of granuloma tissue of the treated group. 
Table 1. Effect of oral administration of the leaf extract of Terminalia coriacea and acetylsalicylic acid (ASA) on paw volume (means \pm SEM) in the carrageenan-induced paw edema model

\begin{tabular}{llllll}
\hline Treatment & $0 \mathrm{~h}$ (baseline) & $1 \mathrm{~h}$ & $2 \mathrm{~h}$ & $3 \mathrm{~h}$ & $4 \mathrm{~h}$ \\
\hline Saline $1 \mathrm{~mL}$ & $0.44 \pm 0.00$ & $0.36 \pm 0.00$ & $0.38 \pm 0.01$ & $0.35 \pm 0.01$ & $0.30 \pm 0.00$ \\
ASA $100 \mathrm{mg} / \mathrm{kg}$ & $0.18 \pm 0.01$ & $0.26 \pm 0.00^{* *}$ & $0.25 \pm 0.01^{* *}$ & $0.24 \pm 0.00^{* *}$ & $0.18 \pm 0.00^{* *}$ \\
TCLME & & & & \\
$125 \mathrm{mg} / \mathrm{kg}$ & $0.40 \pm 0.00$ & $0.30 \pm 0.00^{*}$ & $0.28 \pm 0.01^{* *}$ & $0.26 \pm 0.01^{* *}$ & $0.22 \pm 0.00^{* *}$ \\
$250 \mathrm{mg} / \mathrm{kg}$ & $0.36 \pm 0.00^{* *}$ & $0.30 \pm 0.01^{*}$ & $0.24 \pm 0.00^{* *}$ & $0.26 \pm 0.00^{* *}$ & $0.20 \pm 0.00^{* *}$ \\
$500 \mathrm{mg} / \mathrm{kg}$ & $0.26 \pm 0.00^{* *}$ & $0.26 \pm 0.01^{* *}$ & $0.22 \pm 0.00^{* *}$ & $0.24 \pm 0.00^{* *}$ & $0.18 \pm 0.00^{* *}$ \\
\hline
\end{tabular}

$n=6$. TCLME, methanolic extract of $T$. coriacea leaves. ${ }^{*} p<0.05,{ }^{* *} p<0.01$, vs. control (saline); one-way analysis of variance followed by Dunnett's multiple comparison post hoc test using GraphPad Prism.

Statistical Analysis

The data were analyzed by one-way analysis of variance followed by Dunnett's multiple comparison post hoc test using GraphPad Prism version 6 for Windows (GraphPad Software, San Diego, CA, USA). The values were expressed means \pm SEM. $p<$ 0.05 was considered significant.

\section{Results}

\section{Yield of the Extract}

The yield of the extract was found to be approximately $16 \mathrm{~g}$ with respect to the initial weight of the powdered material.

\section{Carrageenan-Induced Paw Edema Model}

The subplantar injection of carrageenan produced edema in negative control rats. The mean paw volume in negative control ranged from $0.36 \pm 0.00$ to $0.3 \pm 0.00$ (1-4 h). Pretreatment with the extract at all the test doses produced consistently significant inhibition from 1 to $4 \mathrm{~h}$. A mild decrease $(0.30 \pm 0.00 ; p<0.05)$ in paw volume was noticed after treatment with the extract at 125 and $250 \mathrm{mg} / \mathrm{kg}$ at the end of $1 \mathrm{~h}$ (Table 1 ). However, the effects of the extract at $500 \mathrm{mg} / \mathrm{kg}$ and aspirin were analogous $(p<0.01)$ from $1 \mathrm{~h}$ : the mean paw volume was found to be $0.26 \pm 0.00$ in both groups. Following treatment with the extract at $500 \mathrm{mg} / \mathrm{kg}$ and aspirin, the mean paw volume at 3 and $4 \mathrm{~h}$ were found to be similar $(0.24 \pm 0.00$ and $0.18 \pm 0.00 ; p<0.01)$. The test extract at $500 \mathrm{mg} / \mathrm{kg}$ exhibited a progressive decline in paw edema as that of the standard drug at all time points tested after carrageenan injection (Table 1). These observations point toward the antiedematogenic property of $T$. coriacea leaves.

\section{Cotton Pellet-Induced Granuloma Model}

The methanolic extract of $T$. coriacea leaves after oral administration at doses of 125 and $250 \mathrm{mg} / \mathrm{kg}$ significantly decreased the mean weight of wet granuloma to $0.19 \pm$ 0.01 (19.26\% inhibition) and $0.20 \pm 0.01$ (19.78\% inhibition), respectively $(p<0.05)$. Aspirin and the extract at $500 \mathrm{mg} / \mathrm{kg}$ produced comparable and significant $(p<$ $0.01)$ reduction $(0.18 \pm 0.02-20.57 \%$ inhibition and $0.17 \pm$ $0.00-26.84 \%$ inhibition) compared to the negative control $(0.26 \pm 0.00)$ (Fig. 1a). This indicates the antitransudative potential of the extract. Similarly, oral administration of the extract at doses of 125,250 , and $500 \mathrm{mg} / \mathrm{kg}$ led to a significant $(p<0.05)$ decrease in the mean weight of dry cotton pellets to $0.15 \pm 0.00$ versus $0.19 \pm 0.00$ in the negative control group. The percentage inhibition for the 3 test doses was found to be $23.82,26.51$, and $28.78 \%$ respectively. The most significant decrease in the weight of dry granulomatous tissue was produced by acetylsalicylic acid $(0.13 \pm 0.00)$ with $32.19 \%$ inhibition $(p<0.01)$ (Fig. 1b). This highlights the effect of the leaf extract on the proliferative stage of inflammation.

\section{Discussion}

In this study, the methanolic extract of $T$. coriacea leaves showed significant anti-inflammatory activity at all test doses. This biological action was found to be dose dependent and as effective as the positive control (aspirin). The therapeutic potential of the extract could be attributed to the antioxidant activity and its flavonoid content (apigenin, kaempferol, luteolin, myricetin, quercetin, and rutin) [6]. Flavonoids have been reported to possess a wide range of biological actions [20]. In the inflammatory process, the enzymes cyclooxygenase and lipoxygen- 


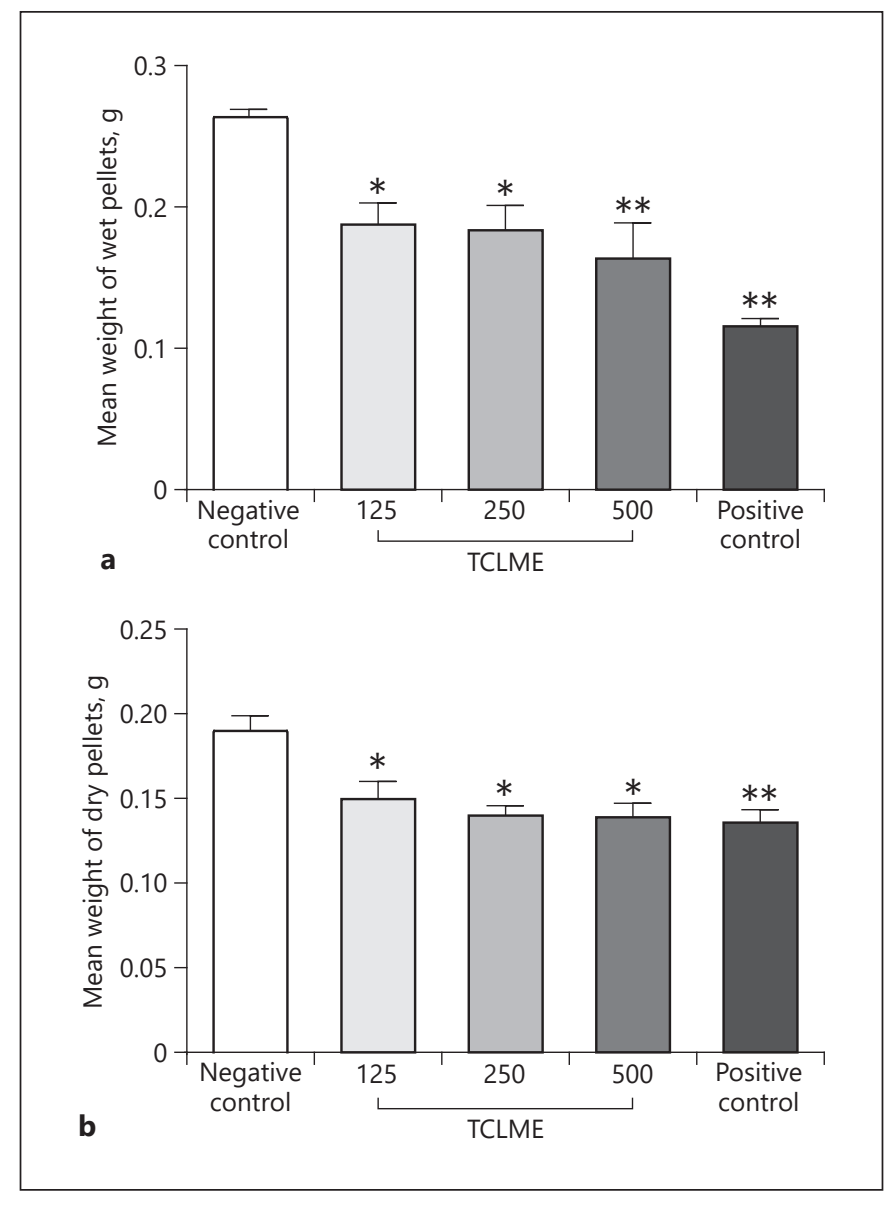

Fig. 1. a Effect of oral administration of the leaf extract on mean wet weight of cotton pellets in the cotton pellet-induced granuloma model. $\mathbf{b}$ Effect of oral administration of the extract on mean dry weights of cotton pellets in the cotton pellet-induced granuloma model. a, b Means \pm SEM $(n=6)$. The positive control was treated with acetyl salicylic acid $100 \mathrm{mg} / \mathrm{kg}$. TCLME, methanolic extract of Terminalia coriacea leaves (mg/kg). ${ }^{*} p<0.05,{ }^{* *} p<$ 0.01 , vs. negative control (normal saline).

ase play important roles causing the release of arachidonic acid, used subsequently by neutrophils containing lipoxygenase to produce chemotactic compounds and simultaneously provoking the release of cytokines [21]. The cyclooxygenase and 5-lipoxygenase pathways that lead to the release of arachidonic acid are inhibited by certain phenolic compounds like quercetin $[21,22]$. Prostaglandin is the end product of the cycloxygenase pathway, and it is involved in various immunologic responses [22]. The synthesis of such an eicosanoid is also inhibited by flavonoids. Moreover, some of the flavonoids also produce vasodilation, which is essential in antinociceptive and anti-inflammatory processes [23]. These compounds also inhibit the action of phospholipase $\mathrm{A}_{2}$ and $\mathrm{C}$ in inflammation besides inhibiting the L-arginine/NO pathway and blocking the protein kinase $\mathrm{C}$ pathway [24, 25]. They are capable of modulating the induction of nitric oxide synthase type-2 (NOS-2) by indirect inhibition of the cyclooxygenase and/or lipoxygenase pathways and nuclear factor- $\kappa \mathrm{B}[26,27]$. They produce anti-inflammatory actions by effectively blocking NOS-2, which induces NO synthesis. The NO inhibition has been found to produce antinociceptive and anti-inflammatory effects $[26,28,29]$. Flavonoids are also capable of inhibiting neutrophil degranulation. This directly diminishes the release of arachidonic acid by neutrophils and other immune cells [30]. The antioxidant and anti-inflammatory properties of the leaf extract give further insights into its healing effects on gastric ulcer [6] and wounds.

Some of the non-flavonoid anti-inflammatory compounds present in leaf extract of $T$. coriacea include $1 \mathrm{H}$-inden-1-one,2,3-dihydro-3,3,5,6,-tetramethyl; neophytadiene; 7,11,15-trimethyl-3-methylene-1-hexadecene; methyl palmitate; palmitic acid, and stigmasterol. The latter 2 compounds are reported to occur at the highest concentrations [11]. These phytochemicals could also play important roles in the anti-inflammatory actions of T. coriacea.

\section{Conclusion}

The observations of the present study, such as decreases in paw volume and wet and dry weights of granulomatous tissue in acute and chronic models of inflammation, suggest that the methanolic leaf extract of $T$. coriacea possesses anti-inflammatory activity particularly at doses of 250 and $500 \mathrm{mg} / \mathrm{kg}$. However, further studies are required to confirm the actual compounds responsible and the mode of action.

\section{Acknowledgments}

The authors thank the management of the Anwarul Uloom College of Pharmacy, Hyderabad, India, for providing the necessary facilities to conduct this project.

\section{Disclosure Statement}

The authors have no conflict of interest to disclose.
Safwan Ali Khan/Khatoon/Al-Sanea/ Gamal Mahmoud/Rahman 


\section{References}

1 Kiritikar KR, Basu BD: Indian Medicinal Plants. Delhi, Periodical Expert Book Agency Publishers, 1991.

2 Chetty KM, Sivaji K, Rao KT: Flowering Plants of Chittoor District, Andhra Pradesh, India, ed 2. Tirupathi, Students Offset Printers and Publishers, 2008.

3 Khan MSA, Hasan MW, Shereen M, et al: Anti-nociceptive effect of Terminalia coriacea (Roxb.) Wight and Arn. leaf methanolic extract. PharmacologyOnLine 2011;7:11761189.

4 Khan MSA, Mat Jais AM, Zakaria ZA, et al: Wound healing potential of Leathery Murdah, Terminalia coriacea (Roxb.) Wight and Arn. Phytopharmacology 2012;3:158-168.

5 Pasha SG, Khateeb MS, Pasha SA, et al: Antiepileptic activity of methanolic extract of Terminalia coriacea (Roxb.) Wight and Arn. in rats. J Adv Pharm Technol Res 2013;3:502510.

6 Khan MSA, Nazan S, Mat Jais AM: Flavonoids and anti-oxidant activity mediated gastroprotective action of Leathery Murdah, Terminalia coriacea (Roxb.) Wight and Arn. leaf methanolic extract in rats. Arq Gastroenterol 2017;54:183-191.

7 Patel J, Reddy AV, Kumar GS, et al: Hepatoprotective activity of methanolic extract of Terminalia coriacea leaves. Res J Pharm Tech 2017;10:1313-1316.

8 Mallavarapu GR, Muralikrishna E, Rao SB, et al: Triterpenoids of the heartwood of Terminalia alata Heyne ex Roth. Ind J Chem Section B 1980;19:713-714.

-9 Mallavarapu GR, Rao SB, Syamsundar KV: Chemical constituents of the bark of Terminalia alata. J Nat Prod 1986;49:549-550.

10 Gahlaut A, Sharma A, Shirolkar A: Non-targeted identification of compounds from regenerated bark of Terminalia tomentosa by HPLC-(+) ESI-QTOFMS. J Pharm Res 2013; 6:415-418.
11 Patel J, Reddy AV, Kumar GS: Gas chromatography and mass spectroscopy analysis of bioactive components on the leaf extract of Terminalia coriacea: a potential folklore medicinal plant. Int J Green Pharmacol 2017; 11:S140-S143.

12 Dunne MW: Concept of altered health states with contributors; in Porth CM (ed): Pathophysiology. Philadelphia, Lippincott, 1990, pp 165-176.

13 Winter CA, Risley EA, Nuss GW: Carrageenan induced edema in hind paw of the rat as an assay for anti-inflammatory drugs. Proc Soc Exp Biol Med 1965;111:544-547.

14 Hajhashemi V, Zolfaghari B, Yousefi A: Antinociceptive and anti-inflammatory activities of Satureja hortensis seed essential oil, hydroalcoholic and polyphenolic extracts in animal models. Med Princ Pract 2012;21:178182.

15 Olajide OA, Makinde JM, Okpako DT: Evaluation of the anti-inflammatory property of the extract of Combretum micranthum G. Don (Combretaceae). Inflammopharmacology 2003;11:293-298.

16 Meier R, Schuler W, Desaulles P: On the mechanism of cortisone inhibition of connective tissue proliferation. Experientia 1950;6: 469-471.

17 Niemegeers CJE, Awoutersm F, Lenaerts FM, et al: The activity of suprofen on nystatininduced paw edema in rats. Arzneimittelforschung 1975;23:1516-1519.

18 Shaik Mossadeq WM, Sulaiman MR, Tengku Mohamad TA, et al: Anti-inflammatory and antinociceptive effects of Mitragyna speciosa Korth methanolic extract. Med Princ Pract 2009; 18:378-384.

19 Okoli CO, Akah PA, Nwafor PA, et al: Antiinflammatory activity of hexane leaf extract of Aspilia Africana. J Ethnopharmacol 2007;109: 219-225.

20 Robak J, Gryglewski RJ: Bioactivity of flavonoids. Pol J Pharmacol Pharm 1996;48:555564.
21 Ferrandiz ML, Alcaraz MJ: Anti-inflammatory activity and inhibition of arachidonic acid metabolism by flavonoids. Agents Actions 1991;32:283-288.

-22 Yoshimoto T, Furukawa M, Yamamoto S, et al: Flavonoids: potent inhibitors of arachidonate 5-lipoxygenase. Biochem Biophys Res Commun 1983;116:612-618.

23 Moroney MA, Alcaraz MJ, Forder RA, et al: Selectivity of neutrophil 5-lipoxygenase and cyclo-oxygenase inhibition by an anti-inflammatory flavonoid glycoside and related aglycone flavonoids. J Pharm Pharmcol 1988;40: 787-792.

24 Middleton EJR, Kandaswami C, Theoharides TC: The effects of plant flavonoids on mammalian cells: implications for inflammation, heart disease, and cancer. Pharmacol Rev 2000;52:673-751

25 Meotti FC, Luiz AP, Pizzolatti MG, et al: Analysis of the antinociceptive effect of the flavonoid myricitrin: evidence for a role of the L-arginine-nitric oxide and protein kinase $\mathrm{C}$ pathways. J Pharm Exp Ther 2005;316:789796.

26 Olszanecki R, Gebska A, Kozlovski VI, et al: Flavonoids and nitric oxide synthase. J Physiol Pharmacol 2002;53:571-584.

-27 Nam NH: Naturally occurring NF-kB inhibitors. Mini Rev Med Chem 2006;6:945-951.

28 Machelska H, Labuz D, Przewlocki R, et al: Inhibition of nitric oxide synthase enhances antinociception mediated by mu, delta and kappa opioid receptors in acute and prolonged pain in the rat spinal cord. J Pharm Exp Ther 1997;282:977-984.

29 Kim HP, Son KH, Chang HW, et al: Antiinflammatory plant flavonoids and cellular action mechanisms. J Pharmacol Sci 2004;96: 229-245.

30 Tordera M, Ferrandiz ML, Alcaraz MJ: Influence of anti-inflammatory flavonoids on degranulation and arachidonic acid release in rat neutrophils. Z Naturforsch C 1994;49: 235-240. 